\title{
Statistical Analysis on Belgian Building Defects
}

\author{
Jasmijn De Vos, Anke Blommaert and Nathan Van Den Bossche
}

\author{
Ghent University, Faculty of Engineering and Architecture, Building Physics Group. Sint \\ Pietersnieuwstraat 41 B4, 9000 Ghent, Belgium.*Nathan.vandenbossche@ugent.be
}

\begin{abstract}
The lack of systematization in the collection of building defects leads to a wide range of data that is not used to its full potential. Unfortunately, this opportunity is missed since lessons could be drawn from analyzing this data by systematically mapping and investigating building defects. This paper presents the results of a statistical analysis on 27074 cases of building defects provided by a Belgian insurance company, ranging from 1991 up to 2019. This analysis focuses on the types of damage, the occurrence in relation to the construction time and the typology of the claims. Spearman correlation tests, $X^{2}$ tests, and Kruskal-Wallis tests are performed to assess the significance of correlations. Moisture problems constitute 49\% of all technical defects, followed by structural issues (19\%), and cracking (17\%). Within the category of moisture problems, the roof is the dominant location for problems to occur, followed by basements, façades, windows, and rising damp. $50 \%$ of the judicial cases were closed after 3 years, whereas cases without lawsuit are typically settled after 1-2 years.
\end{abstract}

Keywords: Building Defects, Pathology, Catalogue, Statistical Analysis, Insurance Company.

\section{Introduction}

Currently, an immense amount of information is available about building defects in the Belgian construction industry. Details about the causes, the damage caused by the defects, the associated repair cost, the liability, etc. can be found in reports of insurance companies, law offices and expertise bureaus, since they are appointed to deal with damage claims. However, the existing information is not fully used to prevent similar mistakes and to limit the number of damage claims in the future, since there is no harmonized data collection, no classification, no structure and no consent in processing the data.

In different countries, initiatives have been taken to create databases on building pathologies. 'Système de collecte des désordres' (France), 'Danish Building Defects Fund' (Denmark), 'Defect Action Sheet' (United Kingdom), 'Patorreb' (Portugal) and 'Learning from Mistakes' (Italy) are only a few initiatives where countries create databases on building pathologies. The CIB (International Council for Research and Innovation in Building and Construction) is a worldwide network concerned with the exchange of information to learn from past and current building pathologies. It achieves what the previously mentioned countries do at national level, on an international level.

Statistical analysis of these data may reveal unidentified patterns and provide insights on the dominant failures in terms of building component, type of damage, cause, time of occurrence, geographical location, building exposure, cost, and the like. Consequently, these insights may help in identifying aspects that need attention, additional guidelines, quality assurance protocols, or prevention, in order to reduce the failure cost in the building industry. This is of great importance since building defects often lead to discussions, and generate high costs, time 
delay, reputation damage, litigations and decreased sustainability.

For property developers, architects and construction managers, the results of the analysis may provide a series of lessons on the critical aspects in order to minimize building defects. The insights derived from the analysis can be used by building professionals, leading to innovative ideas regarding materials, design concepts and construction methods. As a consequence, the quality of the buildings can be enhanced. Higher quality implies better durability, longer service life, lower life cycle cost, lower waste production, and higher sustainability.

\section{Methodology}

A qualitative and representative dataset is a prerequisite for statistical analysis to derive conclusions that can be extrapolated to the Belgian building industry. The analysis presented in this paper was based on the database of the largest Belgian insurance company in the building industry (containing 27074 documented cases), representing the larger share of architects and engineering offices in that field.

Firstly, data are extracted from the insurance company's database, recoded and cleaned. The cleaning of the data is not discussed in this paper, but proved to be essential for the quality of the final dataset and analysis. Note that no statistical data-imputation for missing fields was done. A second step concerns the selection of the statistical tests and their graphical representation in the search for statistical correlations, associations and differences. Because of

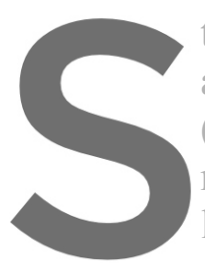
the size of the databas assumed that the variables are (based on the Central number of outliers and limited number of cases, non-parametric statistical testing is executed.
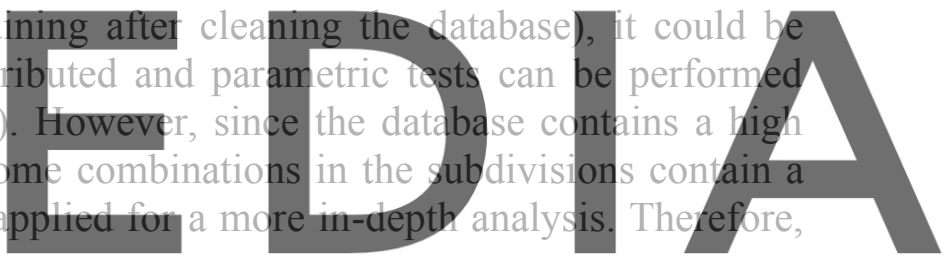

The following three tests are used: Spearman correlation, $X^{2}$ and Kruskal-Wallis. The focus

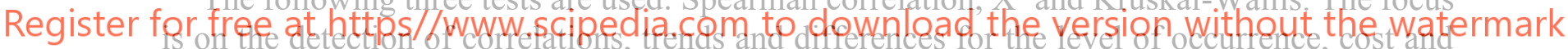
time. The trends and statistical differences are discussed and interpreted in chapter 4, Results. Finaliy, the last chapter provides some conciusions and future perspectives.

\section{The Database}

The database from the insurance company contains 27074 documented cases, which have been processed and filed by either jurists or engineers between 1991 and 2019 working at the company. Since jurists are not trained in building science, there is perhaps a possibility that some damage cases are incorrectly diagnosed or documented in the database. However, for technical more complex cases a construction expert is always consulted, and given that this paper focusses mainly on the overall analysis, it is considered that this effect is negligible for the analysis presented here.

It must be considered that unconscious selection bias is present, as the insurance company mainly focuses on the insurance of the professional liability of architects and contractors. Hence, failures in which an insurance company is not involved (e.g. contractor makes a mistake 
and repairs it) are not covered here. By consequence, the analysis does not provide insights into the complete overall fault cost or construction failures. Nonetheless, this database is a relevant sample of the real 'population' of construction failures, as it can be assumed that the more complex cases are covered, and as well the important failures in terms of associated costs.

\section{Results}

\subsection{Damage Categories}

Using descriptive statistics, the occurrence hierarchy of the nine categories of damage is shown in figure 1.
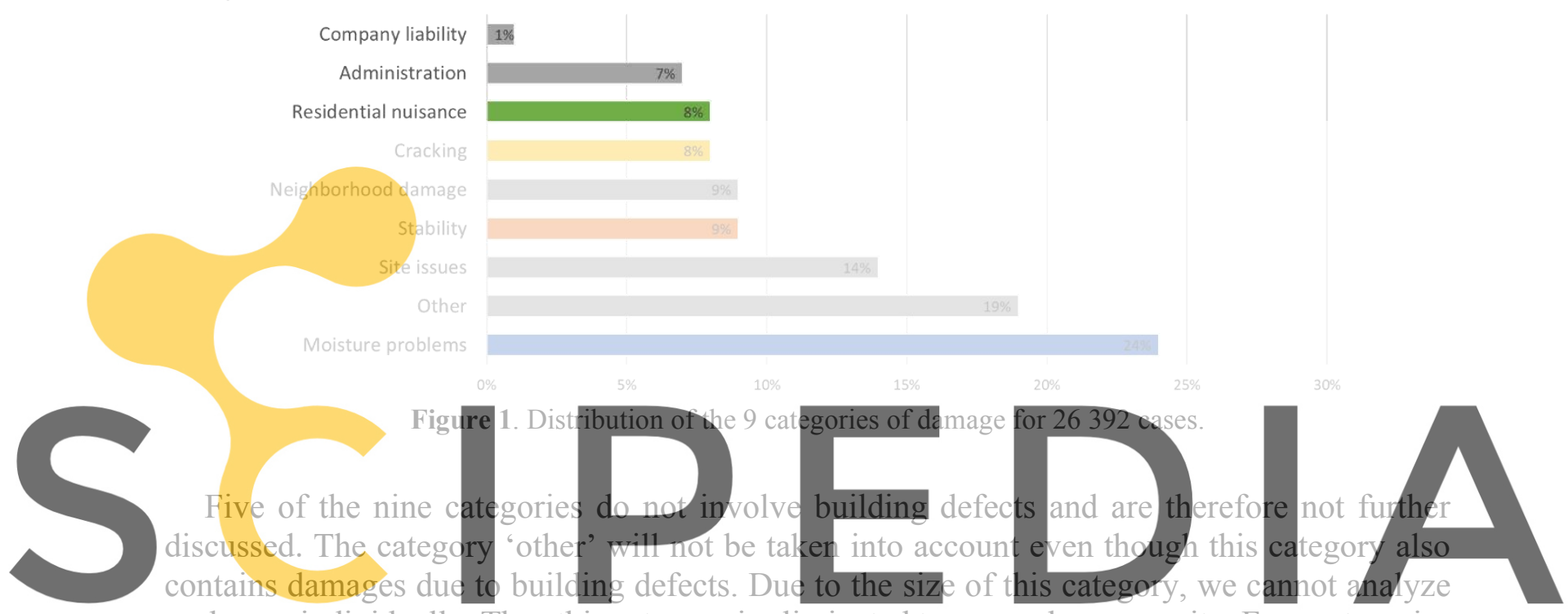

each case individually. Thus this category is eliminated to ensure homogeneity. Four categories

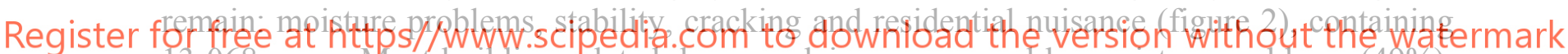
13068 cases. Most building related damage claims are caused by moisture problems (49\%).

Cracking, residential nuisance and stability have a similarly smaller share of 16-19\%.

The distribution of the damage types within the different categories is also shown in figure 2. For moisture problems, the two mayor problems are concerning water infiltration in the roof (24\%) and the basement (21\%), while all other problems only occur less than $10 \%$ of the time. It must be noted that the subcategories contain labels according to location and type. This makes it unclear how, for example, 'condensation problems in the roof' should be categorized.

For stability, the roof $(27 \%)$ is the most affected apart from the $49 \%$ of cases which is categorized as "General stability problems". These general stability problems regard the general load-bearing structures like walls, beams and columns with the exclusion of the separate categories.

For cracking, the lack of a detailed categorization obstructs the opportunity for a more indepth analysis. Cracks could have been formed due to stability or moisture problems.

For residential nuisance, the damage is the most often categorized as sewage problems $(22 \%)$, defective material (12\%), heating problems (11\%) and finishing (11\%). 

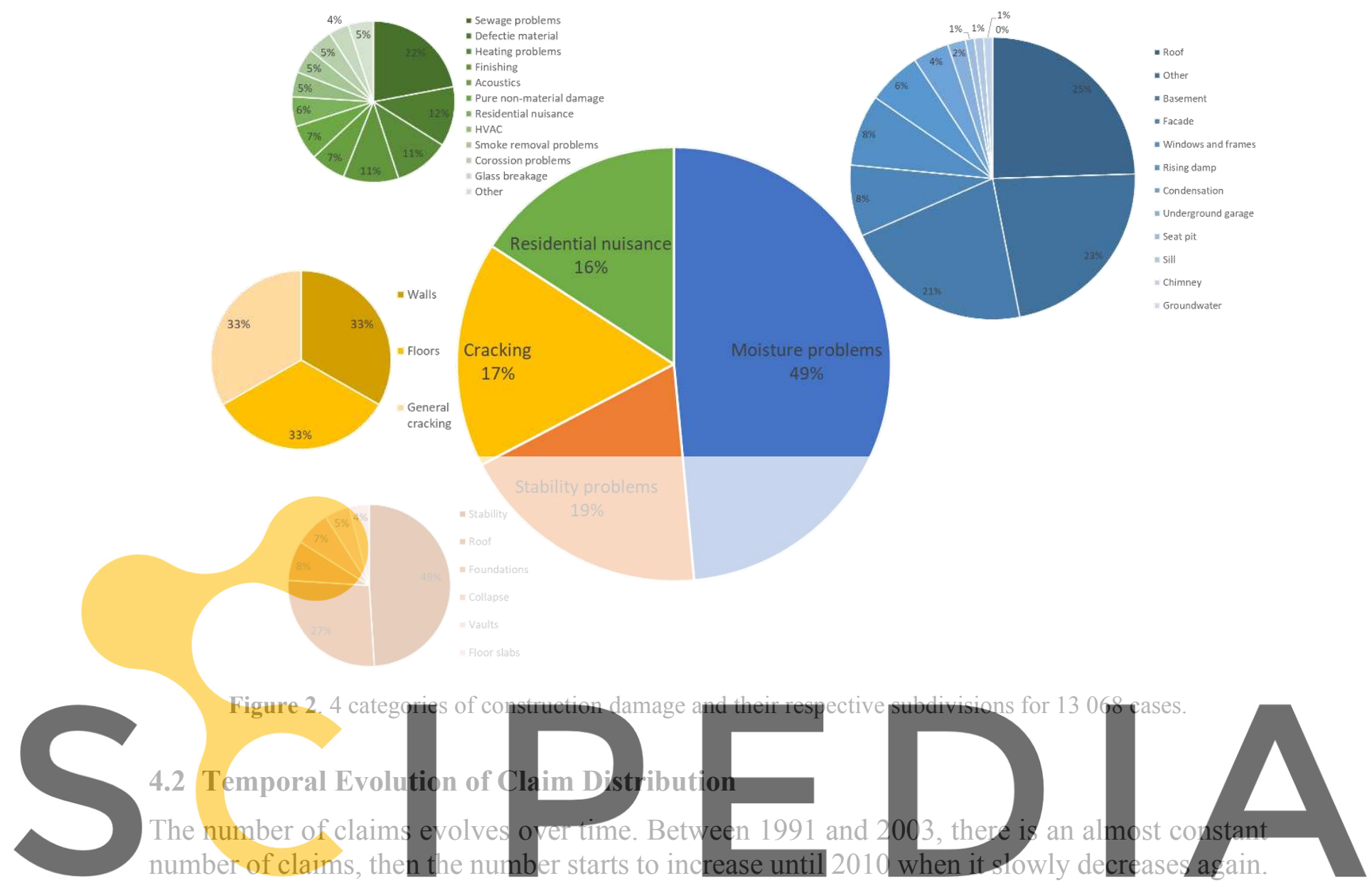

The reason why numbers start to increase in 2003 is that the insurance took over a competitor

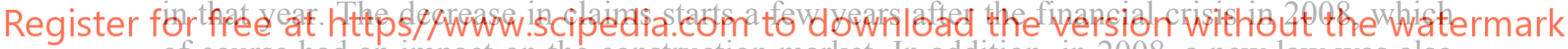
of course had an impact on the construction market. In addition, in 2008, a new law was also introduced regarding the compensation of court costs: the losing party must pay the winning party a fee to compensate juridical costs. In 2010, the insurance company also decided to introduce prevention measures to cover contract initiations and contract problems and starts to provide advice and assistance to the insured professionals when a rise of the imminent defects can be noticed, which also might partially explain the decrease over the last decade. However, it can be concluded that the overall number of cases in the database is affected by the company structure, the variable market share over time, the work volume in the construction industry (business cycle), evolution of construction standards and guidelines, prevention measures, and the like. Although it is generally acknowledged that the introduction of the EPBD in 2006 has had a clear impact on the building sector and changed building component compositions drastically, it is yet unclear to what extent that change has resulted in an associated rise (learning curve for new methods) or decline (more quality control and larger buffers) in failures.

When we look at the distribution of the types of damage per year, it is observed that the percentages fluctuate over time. From 2001, an increase of 'neighborhood damage', is detected. 
The latest ten years a small decrease in the number of 'site issues' (measurement and calculation errors, delivery problems, delays, budget exceedance,...) is noticed (figure 3 ).

When only the four main types of damage are considered (moisture problems, stability, cracking and residential nuisance), we see that 'moisture problems' remains the most occurring damage type.

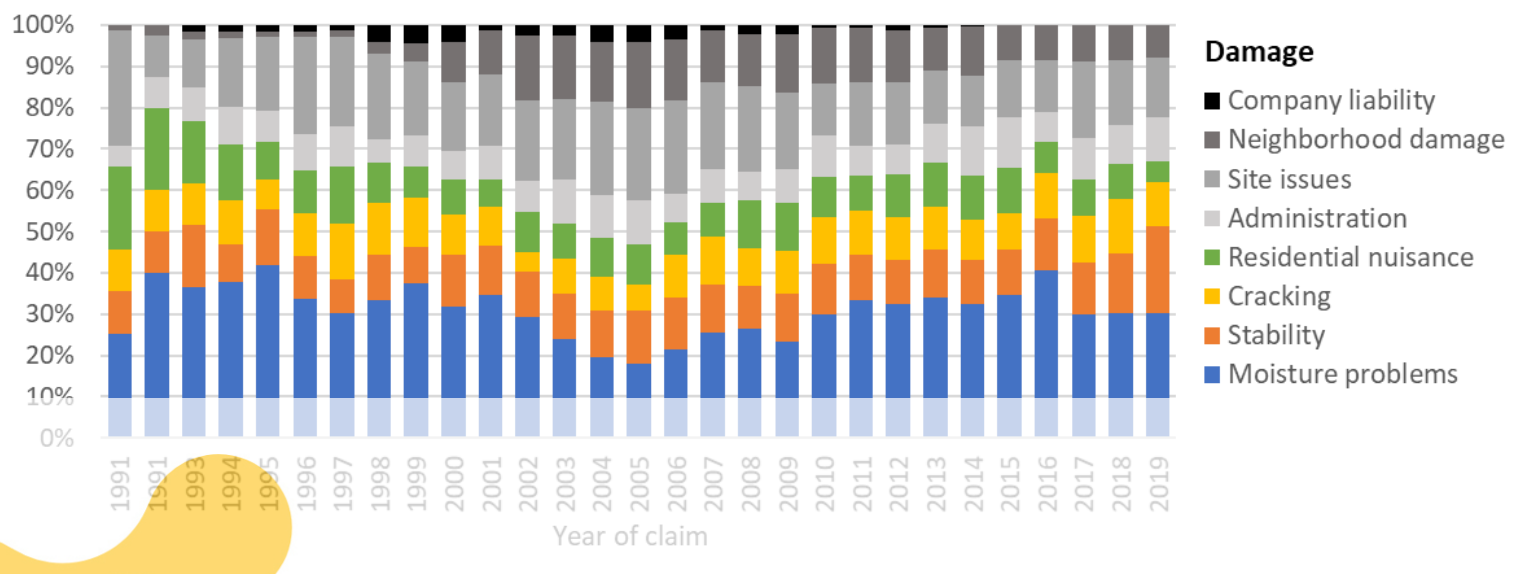

Figure 3. Evolution of the distribution of types of damage over time.

\subsection{Moment of Occurrence in the Building Process}

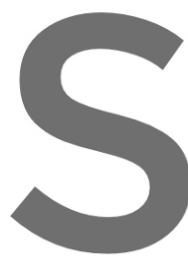

Damage claims can occu acceptance (PA), the fin

year after the final acceptance (the end of

In figure 4 it is observed that in $47 \%$ of the cases, damage occur

acceptance and in $28 \%$ of the cases, damag
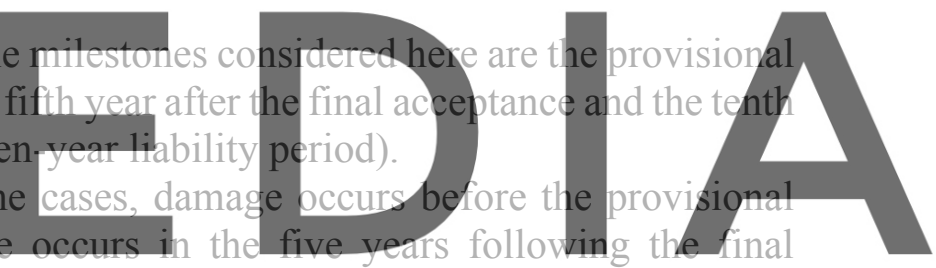

acceptance. It makes sense that there are almost no damages found after more than 10 years.

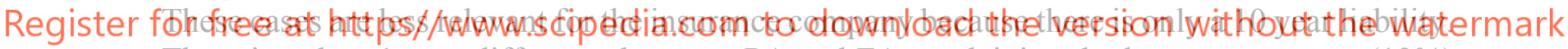

There is only a 1 year difference between PA and FA, explaining the lower percentage (13\%)

in this interval.

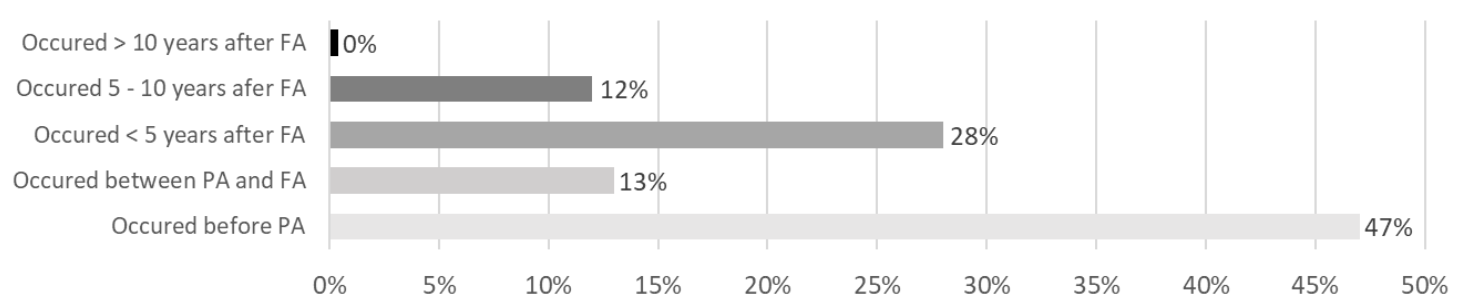

Figure 4. Bar chart: Distribution time (delivery).

The $\mathrm{X}^{2}$ - test for 'Damage' and 'Time delivery' indicates various significances. Figure 5 shows that stability problems mainly arise even before the final acceptance has taken place and that moisture problems mainly occur within five years after the final acceptance. Only $15 \%$ $25 \%$ of the cases are reported between five and ten years after the final acceptance. Therefore, 
from these data, it can be concluded that stability problems occur early in the construction process and that cracking and moisture problems arise later.

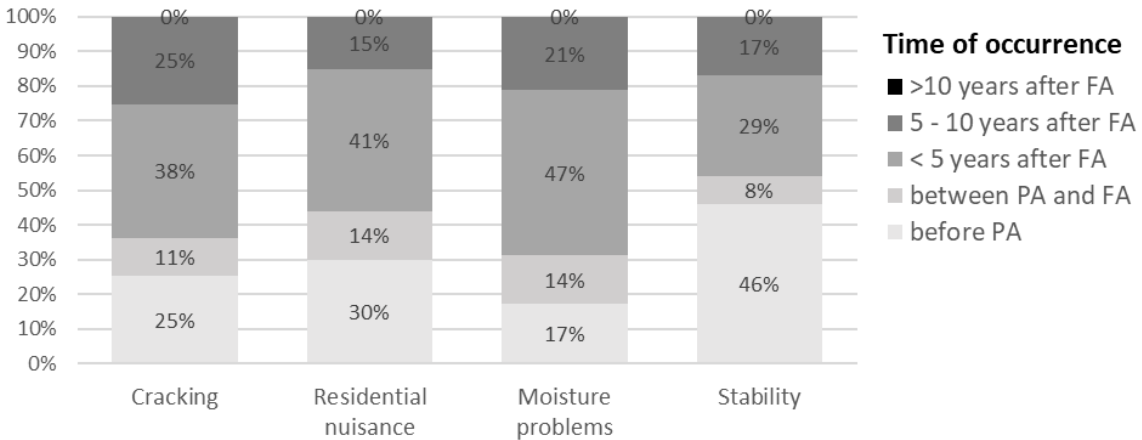

Figure 5. Analysis of time of occurrence in the building process (delivery) for the 4 main categories

Next, the four main categories are considered separately and conclusions are drawn for aspects for which relevant significances were found. No extreme exceptions are found for moisture problems. Water infiltration of roofs and basements occurs in more than $30 \%$ of the cases before the final acceptance. At first sight this appears to be in contrast to the general conclusion above on the occurrence of moisture problems. However, it should be noted that these building components typically adopt a perfect barrier watertightness concept: flat roofs and basements do not incorporate drainage or buffering systems which may result in a quick appearance of building defects. Next to that, both building loads irrespective of coon buildings). Althougl buffering is not present. Rising đamp occurs after delivery, while for the other moisture prole

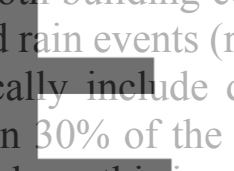

damp is a phenomenon that takes more time to develop, while water infiltration to roofs and

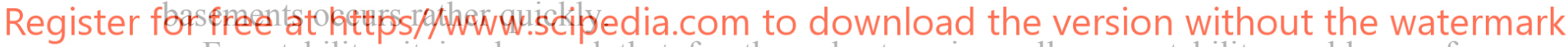

For stability, it is observed that for the subcategories collapses, stability problems of foundations, and roofs, more than 50\% occurs before final acceptance. On the other hand, for the stability of vaults and floor slabs this is between five and ten years after final acceptance. Collapses are probably mainly attributed to demolition and renovation works.

It seems remarkable that residential nuisance is already reported before the provisional acceptance (figure 5). However, this result can be explained by looking more in detail to the specifications of residential nuisance (figure 6). Damage related to finishing, color, aesthetics and pure non-material damage occur mainly before the provisional acceptance. These defects are detected when the material is supplied or when the construction is still in progress. As expected, corrosion and moss growth occur later in time. 


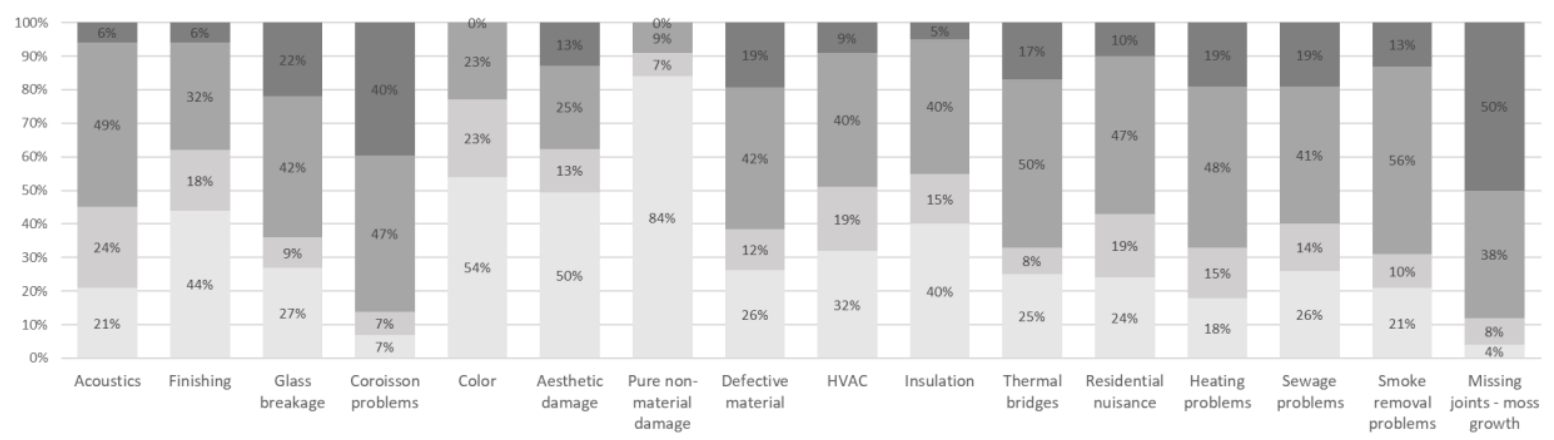

Figure 6. Specification residential nuisance versus time of occurrence (delivery)

\subsection{Damage and Type of Settlement}

The type of settlement reveals information on the complexity. There are three types of settlement: Amicable settlements without appointment of experts, amicable settlements with appointment of experts and juridical files with appointment of lawyers. An amicable settlement of a dispute is a settlement that satisfies both the parties. Juridical files are generally speaking more difficult. The different categories all have about the same amount of judicial files.

Therefore, the $\mathrm{X}^{2}$ - test for 'Damage' and 'Type of settlement' indicates that specific types of damage are more complicated than others. Since stability is more complex, it is less classified as amicable settlements without the appointment of experts (only $18 \%$ of cases in this category) than residential nuisance $(32 \%)$, moisture problems $(27 \%)$ 4.5 Time of Occurrence The $\mathrm{X}^{2}$ - test between 'Time delivery' and 'Type of settlement' Damages occurring in the tenth year after the accentanc
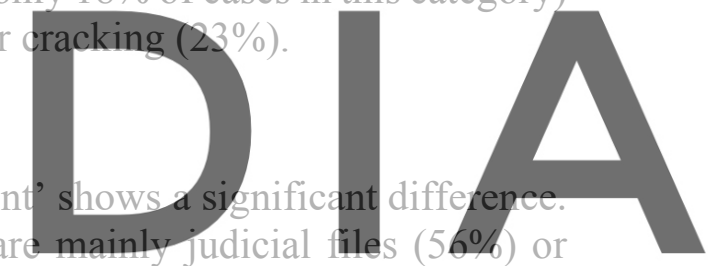
amicable settlements without appointment of experts (38\%). The type amicable settlements

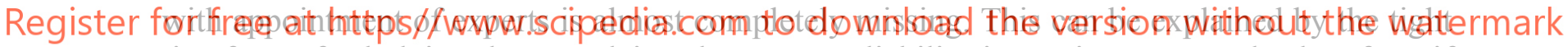
timeframe for lodging the complaint: the ten-year liability is coming to an end. Therefore, if necessary, it is classified as judicial, but if it can quickly be solved in an easy way, it is classified as amicable settlement without appointment of experts.

\section{Conclusions}

The database analyzed here comprises four main types of damage related to building defects: moisture problems, stability, cracking and residential nuisance. It was concluded that moisture problems, mainly water infiltration and rising damp, account for about half of the building defects. Even though the number of damage claims evolves over time, water infiltration remains the prominent claim. It must be noted that there are a lot of inconsistencies regarding the categorization of the cases. The subcategories, for instance, contain labels according to location and type. This makes it unclear how certain cases should be categorized.

Some types of damage are more complex than others. Stability is more complex since they are less classified as amicable settlements without the appointment of experts than residential 
nuisance, moisture problems or cracking.

Most problems occur before the final acceptance. When we look at each type of damage individually, we notice that each type of damage occurs at different times. Moisture problems, cracking and residential nuisance occur later in time, compared to stability problems. Within the cases considering stability, especially collapses or damage arising at the foundations are the ones to occur before the provisional acceptance. For the cases considering moisture problems, rising damp occurs later than all other types of water damage.

For damages occurring in the tenth year after the acceptance, there are almost no amicable settlements with appointment of experts. This can be explained due to the tight timeframe for lodging the complaint, the ten-year liability is coming to an end. Therefore, if necessary, the complaint is classified as judicial, but if it can be easily solved, it is classified as amicable settlement without appointment of experts.

\section{Acknowledgements}

The authors would like to thank the insurance company for the access to the database, information and insights, and fruitful collaboration.

\section{ORCID}

Nathan Van Den Bossche: https://orcid.org/0000-0002-8738-7249

Anke Blommaert: https://orcid.org/0000-0002-8427-7300

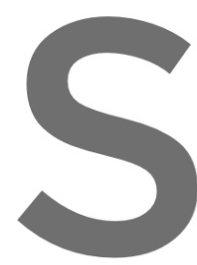

References

Carretero-Ayuso, M.J., A. Moreno-Can roofs, Revista De La Con

de Freitas, V.P. (2013). Innovation in Building

De Vos, J. (2019). Building defects in
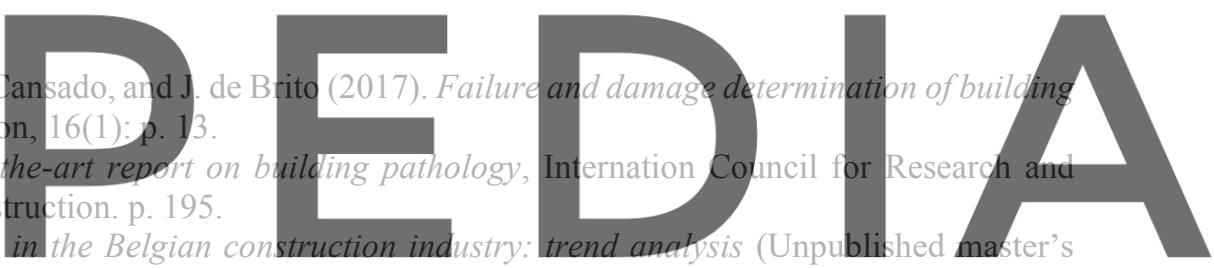

thesis), Ghent university, Faculty of Engineering and Architecture.

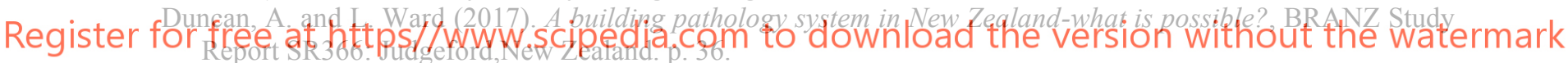

Molnárka, G.J.B. (2000). Problems in Failure Analysis in Building Pathology, p. 129-142.

W086, C. (1993). Building pathology_A state-of-the-art report, Internation Council for Research and Innovation in Building and Construction. p. $7 \overline{8}$.

Abdul-Malak, M.A.U., M.M.H. El-Saadi, and M.G. Abou-Zeid (2002). Process model for administrating construction claims, Journal of Management in Engineering, 18(2): p. 84-94.

Ferraz, G.T., et al. (2016). State-of-the-Art Review of Building Inspection Systems, Journal of Performance of Constructed Facilities, 30(5): p. 8.

Wetenschappelijk en Technisch Centrum voor het Bouwbedrijf (2014). Contact 2014. (in dutch)

IBM SPSS. Available from: https://www.ibm.com/analytics/spss-statistics-software.

Protect (2013). Bulletin 56, p. 12 (in dutch).

Protect (2002). Tekst analyse van schadegevallen, p. 25. (in dutch)

Notten, F. (2019). Uit de bouwput?, Crisis en opleving in de bouwketen (2005-2015), p. 30. (in dutch)

National Bank of Belgium Online statistics. [cited 201918 May]; Available from: http://stat.nbb.be/?lang=en\&SubSessionId=1ad83e70-cd97-4da7-98c0-7f6b7fc6edd6\#.

Van Den Bossche, T. (2016). Cursus_Verzekeringen, Hogeschool Gent. p. 69.

Van Daele, L. (2017). Een catalogus van bouwgebreken-uitbreiding en analyse, Universiteit Gent. p. 121. (in dutch) 